\title{
Rhinoscleroma presenting as a nasal-palatal mass with
}

\section{airway obstruction [version 1; peer review: 1 approved, 2}

\section{approved with reservations]}

\author{
Mark C Domanski ${ }^{1}$, Alexander Rivero², David E Kardon³ \\ ${ }^{1}$ Division of Otolaryngology, Washington Adventist Hospital, Takoma Park, Maryland, 20912, USA \\ ${ }^{2}$ Division of Otolaryngology, George Washington University, Washington D.C., 20037, USA \\ ${ }^{3}$ Department of Pathology, Washington Adventist Hospital, Takoma Park, Maryland, 20912, USA
}

V1 First published: 09 May 2013, 2:124
https://doi.org/10.12688/f1000research.2-124.v1

Latest published: 09 May 2013, 2:124

https://doi.org/10.12688/f1000research.2-124.v1

\section{Abstract}

We report a case of a 45-year-old male with severe rhinoscleroma. The patient presented to the emergency room with dyspnea from a longstanding nasal-palatal mass. A tracheostomy was required for airway control. While dyspnea in the presence of an upper airway mass is typical of malignancy, consideration of non-oncological etiologies is important. We review the epidemiology, pathology, diagnosis, and treatment of rhinoscleroma.

\section{Keywords}

rhinoscleroma, Klebsiella rhinoscleramitis, palate, tracheostomy

Open Peer Review
Approval Status ?
Feinberg School of Medicine, Chicago, IL, USA
2. Allen M Seiden, University of Cincinnati,
Cincinnati, OH, USA
3. Alkis Psaltis, Stanford University Medical
Center, Stanford, CA, USA
Any reports and responses or comments on the
article can be found at the end of the article.

Corresponding author: Mark C Domanski (mcdomanski@gmail.com)

Competing interests: No relevant competing interests were disclosed.

Grant information: The author(s) declared that no grants were involved in supporting this work.

Copyright: (c) 2013 Domanski MC et al. This is an open access article distributed under the terms of the Creative Commons Attribution License, which permits unrestricted use, distribution, and reproduction in any medium, provided the original work is properly cited. Data associated with the article are available under the terms of the Creative Commons Zero "No rights reserved" data waiver (CC0 1.0 Public domain dedication).

How to cite this article: Domanski MC, Rivero A and Kardon DE. Rhinoscleroma presenting as a nasal-palatal mass with airway obstruction [version 1; peer review: 1 approved, 2 approved with reservations] F1000Research 2013, 2:124 https://doi.org/10.12688/f1000research.2-124.v1

First published: 09 May 2013, 2:124 https://doi.org/10.12688/f1000research.2-124.v1 


\section{Introduction}

Rhinoscleroma is a chronic bacterial infection caused by Klebsiella rhinoscleromatis, a Gram-negative, non-motile, encapsulated bacillus. Due to the low infectivity of the bacteria, chronic exposure is required in order to establish infection. Rhinoscleroma is more frequent in the developing world, and is likely a secondary complication as a result of underdeveloped hygiene infrastructures, poor access to antibiotics, and overcrowded living conditions. Most cases are found in Central America, Africa and the Middle East ${ }^{1}$. The prevalence of sporadic cases outside of endemic areas is usually attributed to immigration ${ }^{2}$. Though rhinoscleroma can involve any structure of the upper respiratory tract, Klebsiella rhinoscleromatis has an affinity for nasal mucosa and thus is present in the nasal cavity in $95-100 \%$ of cases ${ }^{3}$. It can also be found in the nasopharynx $(18-43 \%)$, larynx (15-40\%), trachea (12\%), and bronchi $(2-7 \%)^{4}$. Here, we present a case with both nasal and palatal involvement resulting in airway obstruction.

\section{Case report}

A 45-year-old Central American male presented with a 13-year palatal mass, and new onset stridor in the background of chronic dyspnea. He denied weight loss and night sweats. He worked as a day laborer, drank socially, but never smoked. He had been unable to breathe out of his nose for at least thirty years.

Nasal endoscopy showed obstructed choana bilaterally. Inspection of the oral cavity showed a hard, plaque like growth involving the hard and soft palates, pharynx, and marked foreshortening of the palatoglossal folds (Figure 1). Dentition was poor. Endoscopic visualization of the larynx could only be performed transorally. The patient's airway was tight at the level of the palatoglossal folds and base of the tongue. The vocal cords and epiglottis were uninvolved.

A computed tomography (CT) scan confirmed a palatal mass, and obstructed choana. Thickening of the uvula, and hard and soft palate mucosa was noted. No palatal bony obstruction or lymphadenopathy was seen (Figure 2).

A local awake tracheostomy was performed to provide a secure airway. A palatal biopsy was sent for analysis and demonstrated squamous mucosa with a dense, mixed inflammatory infiltrate containing abundant plasma cells and scattered vacuolated macrophages (Mikulicz cells) (Figure 3). A Warthin-Starry stain revealed rod-shaped bacilli within the vacuolated macrophages. The bacilli were morphologically consistent with Klebsiella (Figure 4).

The patient was treated with ciprofloxacin $500 \mathrm{mg}$ BID for 12 weeks. His airway symptoms improved and he was later decannulated without sequelae. He declined surgical nasal airway debridement.

\section{Discussion}

Rhinoscleroma generally progresses in three stages. The initial stage is the catarrhal or exudative phase. This is followed by the

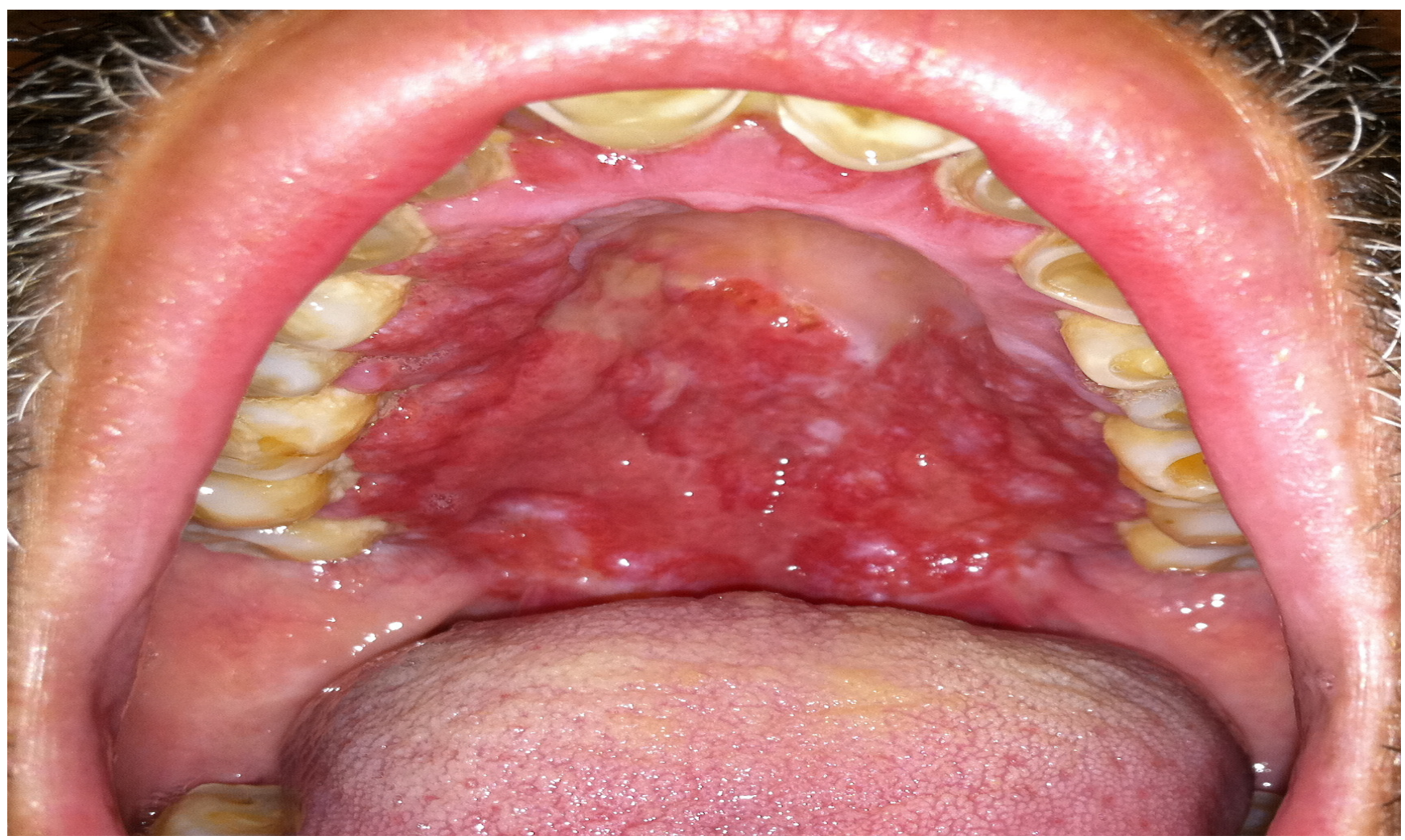

Figure 1. Oral cavity showing a plaque-like erythematous mass involving the gingiva, hard and soft palates. 


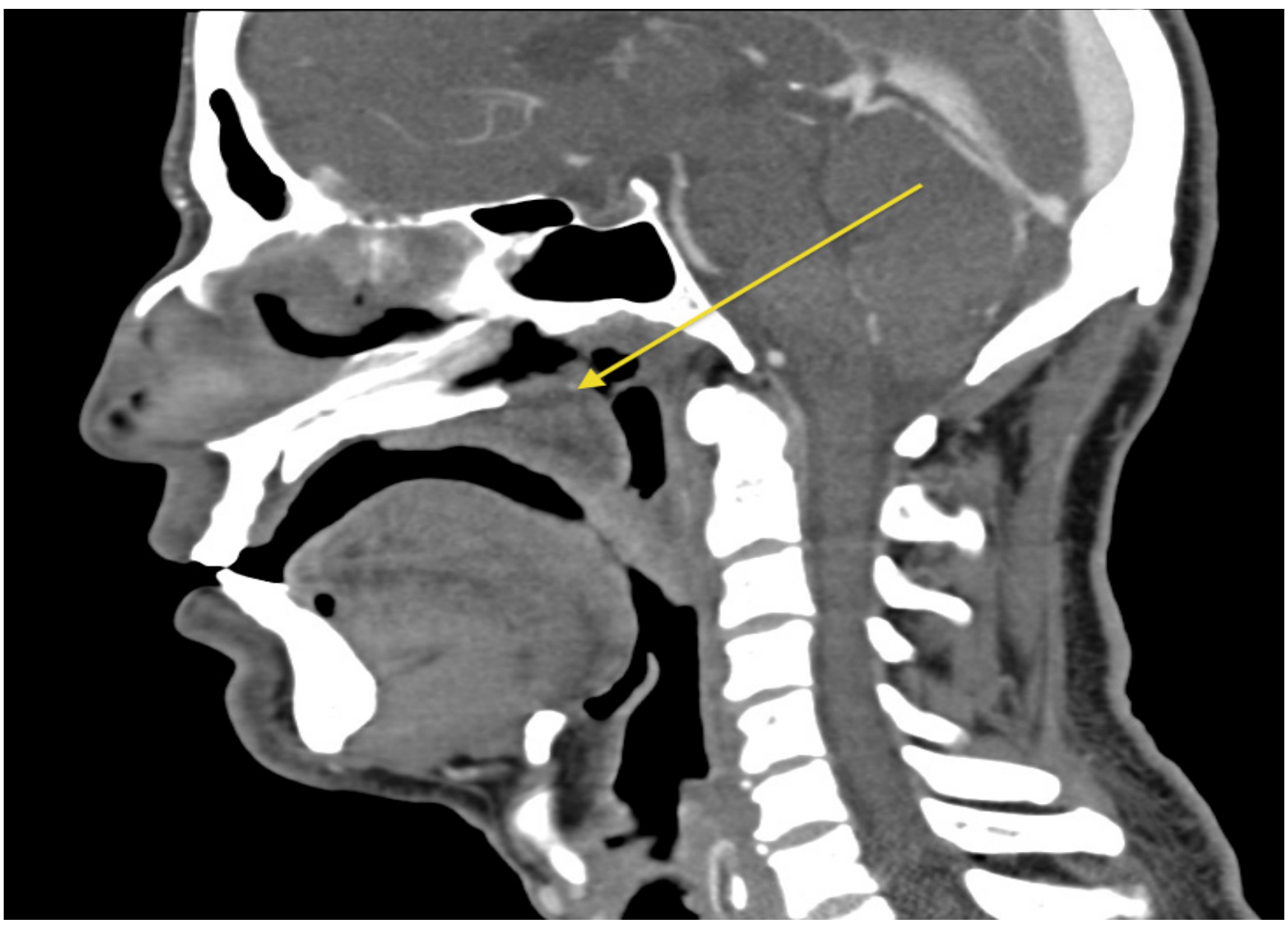

Figure 2. CT neck with contrast in sagittal plane. Heterogeneous soft tissue is present in the nasopharynx.

proliferative or granulomatous phase, which finally evolves into the cicatricial phase ${ }^{2}$. During the catarrhal stage, patients may have persistent rhinitis and mucopurulent discharge. In the second stage, inflamed mucosa coalesces to form granulomas. These granulomas may infiltrate other portions of the airway and then scar, giving rise to the third or cicatricial stage ${ }^{2}$. These stages usually do not exist independently. In many cases of rhinoscleroma, the presence of all three stages can be found at the time of diagnosis.

Rhinoscleroma is spread by person-to-person transmission. However due to the low infectivity of the pathogen, transmission requires a chronic exposure. It has also been proposed that an altered immune response along with an alteration in the CD4+ and CD8+ proportion leads to ineffective macrophage production that are susceptible to bacterial replication ${ }^{5}$.

A high degree of suspicion is warranted when patients present with persistent, unremitting rhinitis or nasal obstruction unexplained by other causes. The differential diagnosis of such symptoms should include rhinoscleroma, as well as tuberculosis, syphilis, Wegener's granulomatosis, lymphomas as well as more common carcinomas. Histopathologic evidence of rhinoscleroma includes granulomatous inflammation with large vacuolated histiocytes known as Mikulicz cells ${ }^{6}$. Canalis et al. proposed that these Mikulicz cells arise from histiocytes that migrate to areas where neutrophils have failed to contain the Klebsiella infection ${ }^{7}$. The histiocytes, however, are unable to lyse their phagocytosed Klebsiella cells, leading to the dilation of their vacuoles? ${ }^{7}$. Positive culture of rhinoscleroma on MacConkey agar is diagnostic, though culture is only positive in $50-60 \%$ of patients. Thus, it is key to have high clinical suspicion in conjunction with positive histopathologic evidence to confirm the diagnosis.

Historically, treatment of rhinoscleroma was with tetracyclines and aminoglycosides such as streptomycin. However, a prospective study done in the Mayo Clinic, USA, by Andraca et al. in 1993 demonstrated the efficacy of fluoroquinolones ${ }^{8}$. Treatment with fluoroquinolones also confers the benefit of a lower side-effect profile. Dosing of the antibiotic is variable between different studies, but most agree that long-term therapy for months and sometimes years is necessary to adequately treat the infection ${ }^{3,7,8}$. Despite treatment, recurrence has been reported in up to $25 \%$ of cases at 10 years $^{2,4}$. Consideration should be made when addressing whether a patient requires surgical de-bulking of the 


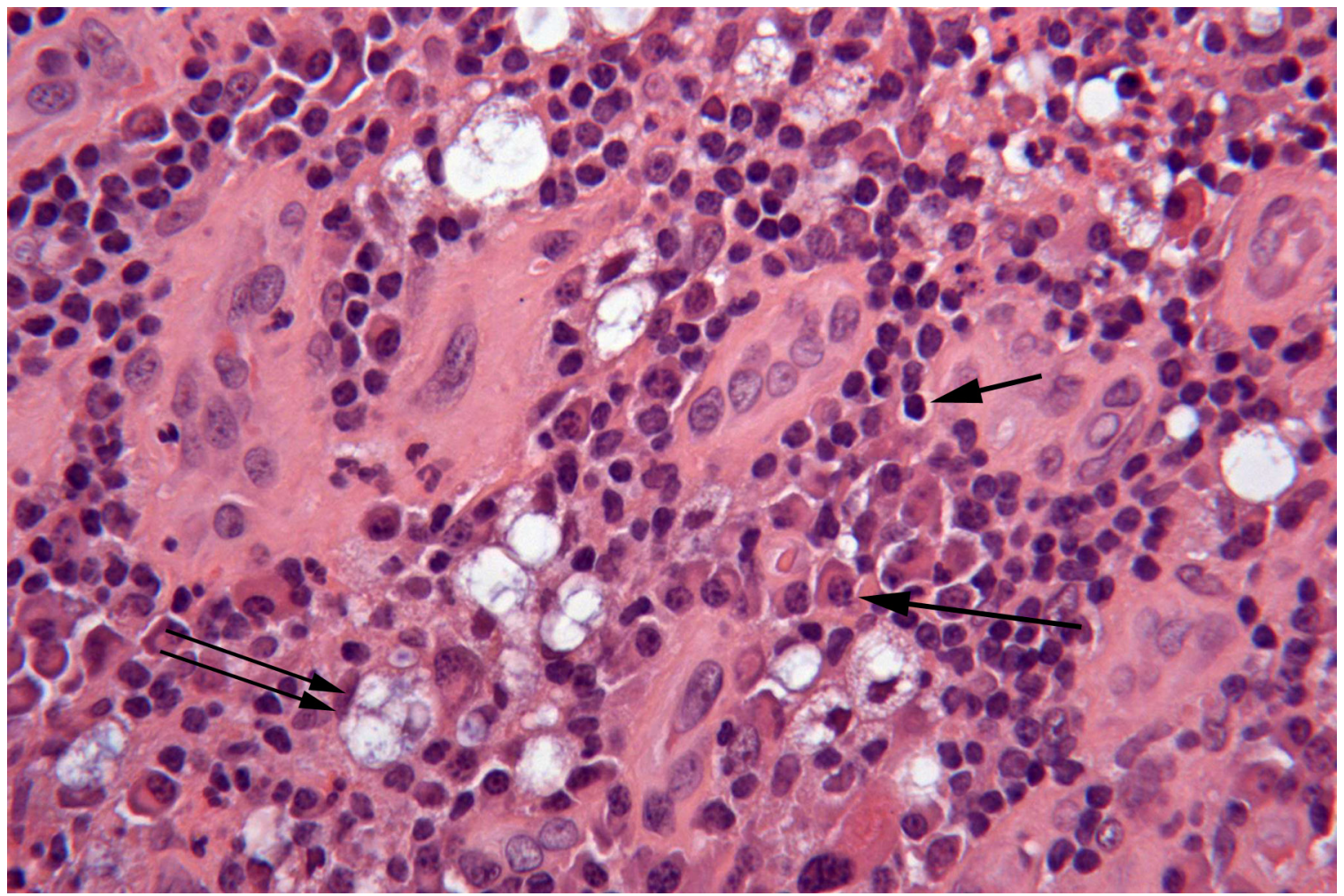

Figure 3. H\&E stain (400x) demonstrated a mixture of plasma cells (arrow), lymphocytes (short arrow) and vacuolated macrophages (Mikulicz cells) (double arrow).

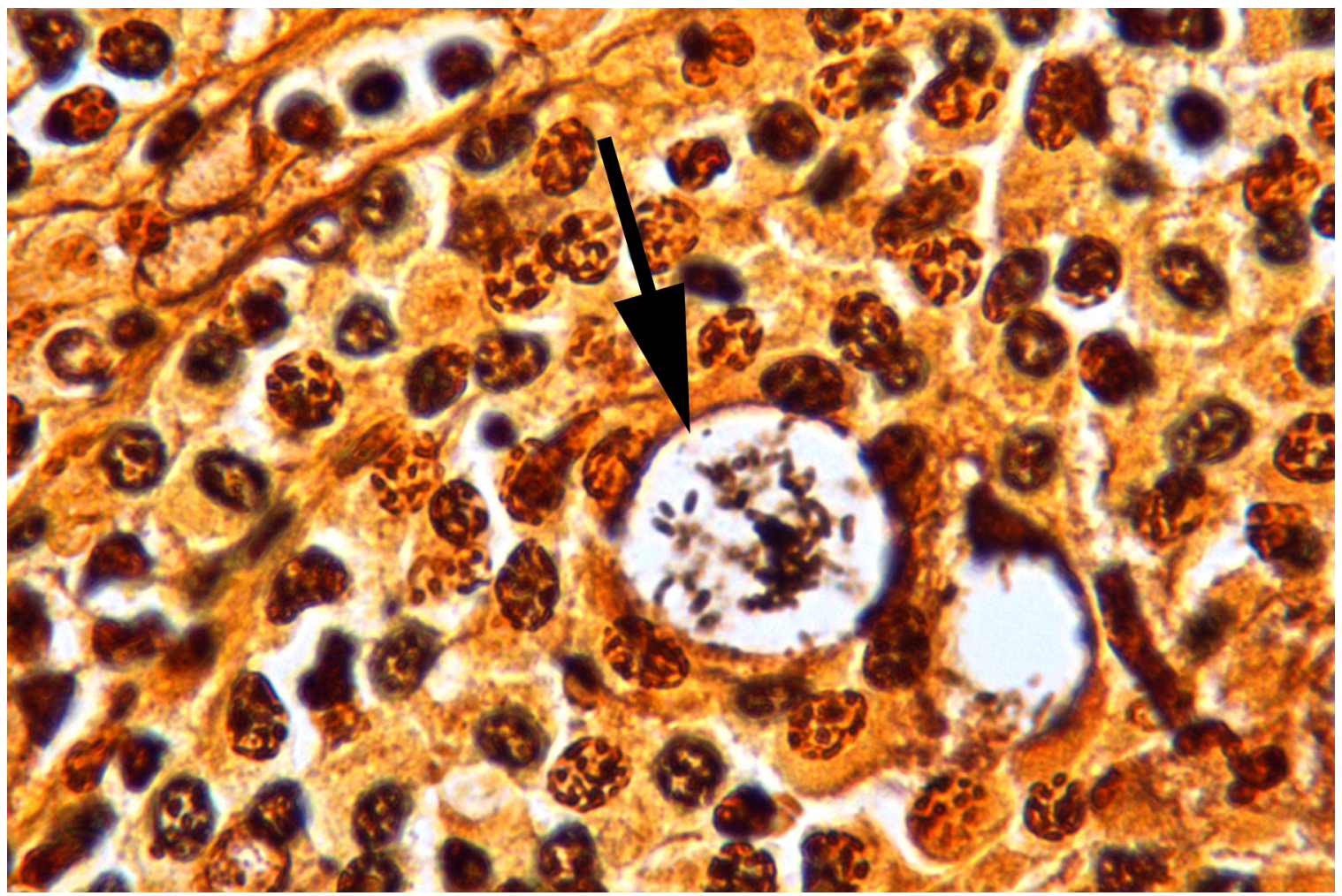

Figure 4. Steiner stain, (1000x) with rod-shaped bacilli within a vacuolated macrophage (Mikulicz cell) (arrow). 
scar in rhinoscleroma formed during the cicatricial stage. Indications for surgical de-bulking include airway patency, treatment of bulky disease, and cosmesis.

\section{Conclusion}

Rhinoscleroma is due to chronic and indolent Klebsiella infection. Symptoms may include chronic, unremitting rhinitis or nasal obstruction that is present for years. The presenting symptom can also be more dramatic, such as airway compromise, as seen in this case. A diagnosis of rhinoscleroma is made via pathological specimens. Communication between the clinician and the pathologist as to the possibility of non-oncological processes can aid in determining the diagnosis. A Warthin-Starry stain demonstrating rod-shaped bacilli within vacuolated macrophages (Mikulicz cells) is classic for rhinoscleroma. Mainstay of treatment is long-term fluoroquinolones. Evaluation of airway patency is critical and surgical intervention may be required.

\section{Consent}

Written informed consent for publication of clinical details and clinical images was obtained from the patient.

\section{Author contributions}

MD treated the patient. DK prepared the pathological slides, which made the diagnosis. AR prepared the first draft of the manuscript. All authors were involved in the revision of the draft manuscript and have agreed to the final content.

\section{Competing interests}

No relevant competing interests were disclosed.

\section{Grant information}

The author(s) declared that no grants were involved in supporting this work.
1. Miller RH, Shulman JB, Canalis RF, et al.: Klebsiella rhinoscleromatis: a clinical and pathogenic enigma. Otolaryngol Head Neck Surg (1979). 1979; 87(2): 212-21. PubMed Abstract

2. Stiernberg CM, Clark WD: Rhinoscleroma--a diagnostic challenge. Laryngoscope. 1983; 93(7): 866-70. PubMed Abstract | Publisher Full Text

3. Yigla M, Ben-Izhak O, Oren I, et al.: Laryngotracheobronchial involvement in a patient with nonendemic rhinoscleroma. Chest. 2000; 117(6): 1795-8. PubMed Abstract | Publisher Full Text

4. Gaafar HA, Gaafar AH, Nour YA: Rhinoscleroma: an updated experience through the last 10 years. Acta Otolaryngol. 2011; 131(4): 440-6. PubMed Abstract | Publisher Full Text
5. Sood N, Sood S, Arora S, et al.: Cytohistological features of rhinoscleroma. Indian J Pathol Microbiol. 2011; 54(4): 806-8.

PubMed Abstract | Publisher Full Text

6. Robbins JB, Riedel BD, Jones T, et al:: Nasal tumor in a Peruvian man. Am J Dermatopathol. 2004; 26(3): 248. PubMed Abstract

7. Canalis RF, Zamboni L: An interpretation of the structural changes responsible for the chronicity of rhinoscleroma. Laryngoscope. 2001; 111(6): 1020-6. PubMed Abstract | Publisher Full Text

8. Andraca R, Edson RS, Kern EB: Rhinoscleroma: a growing concern in the United States? Mayo Clinic experience. Mayo Clin Proc. 1993; 68(12): 1151-7. PubMed Abstract | Publisher Full Text 


\title{
Open Peer Review
}

\section{Current Peer Review Status: ? $\checkmark$ ?}

\section{Version 1}

Reviewer Report 31 May 2013

https://doi.org/10.5256/f1000research.1278.r979

(C) 2013 Psaltis A. This is an open access peer review report distributed under the terms of the Creative Commons Attribution License, which permits unrestricted use, distribution, and reproduction in any medium, provided the original work is properly cited.

\begin{abstract}
Alkis Psaltis
Stanford University Medical Center, Stanford, CA, USA

The authors present an interesting case report of a condition not commonly seen in developed countries. Its unusual presentation reaffirms the need for otolaryngologists to consider infectious processes in the work up of sinonasal and nasopharyngeal masses. The paper is concise, well written and easy to follow. It provides a nice summary of rhinoscleroma particularly of the histopathophysiological features essential for diagnosis.

Additional photographs demonstrating the encroachment of the mass on the pharyngeal airway (i.e. with the use of a tongue depressor), a nasal endoscopic view and a post treatment view may have been helpful in providing more visual information for the reader.
\end{abstract}

I agree with the previous reviewer's concern regarding the need for an awake tracheotomy for the management of the airway. Given the superior appearance of the mass on the sagittal CT scan and the fact that the authors state that an adequate visualization of the uninvolved vocal cords and epiglottis was obtained with transoral endoscopy, why did the authors not consider awake fiber-optic endoscopic intubation or at least mention this as an alternative for managing the airway.

The discussion of the response of the mass to treatment is a little brief. I think additional information would be useful to the reader such as: Percentage decrease in the size of the mass with treatment, how the authors deemed that 12 weeks of treatment was appropriate, progress post treatment and also any scheduled future follow up.

Competing Interests: No competing interests were disclosed.

I confirm that I have read this submission and believe that I have an appropriate level of expertise to confirm that it is of an acceptable scientific standard, however I have significant reservations, as outlined above. 
Reviewer Report 16 May 2013

https://doi.org/10.5256/f1000research.1278.r954

(C) 2013 Seiden A. This is an open access peer review report distributed under the terms of the Creative Commons Attribution License, which permits unrestricted use, distribution, and reproduction in any medium, provided the original work is properly cited.

\section{Allen M Seiden}

Department of Otolaryngology, College of Medicine, University of Cincinnati, Cincinnati, $\mathrm{OH}$, USA

This is an interesting case report describing an unusual presentation for rhinoscleroma, an infectious problem that we see rarely in the USA. It is well written, and well-organized. It would have been interesting to include patient photos post treatment. It can be a difficult diagnosis to make, so a more thorough literature review discussing potential physical findings on presentation would also have been helpful.

Competing Interests: No competing interests were disclosed.

I confirm that I have read this submission and believe that I have an appropriate level of expertise to confirm that it is of an acceptable scientific standard.

Reviewer Report 15 May 2013

https://doi.org/10.5256/f1000research.1278.r941

(C) 2013 Chandra R. This is an open access peer review report distributed under the terms of the Creative Commons Attribution License, which permits unrestricted use, distribution, and reproduction in any medium, provided the original work is properly cited.
Rakesh K Chandra
Department of Otolaryngology - Head and Neck Surgery, Northwestern University Feinberg School of Medicine, Chicago, IL, USA
The manuscript is an excellent review of the topic and is well illustrated with a clinical photo, radiology, and histopathology. My only area of concern is that I wonder whether it was indeed necessary to perform a tracheotomy on this patient. If the glottis was visible transorally, and given the findings on the sagittal radiologic image shown, it looks like the patient could have been intubated. Also the lesion is too superior to cause true stridor. It could be argued that tracheotomy was advised because the patient would have had difficulty managing secretions and there was concern the lesion would swell or bleed upon biopsy, but it is difficult to imagine true stridor and that this patient couldn't have been intubated. The report would be improved if the authors justify their decision to perform the tracheotomy in the light of these comments Title and Abstract are appropriate and the conclusions are otherwise balanced and justified. 
Competing Interests: No competing interests were disclosed.

I confirm that I have read this submission and believe that I have an appropriate level of expertise to confirm that it is of an acceptable scientific standard, however I have significant reservations, as outlined above.

The benefits of publishing with F1000Research:

- Your article is published within days, with no editorial bias

- You can publish traditional articles, null/negative results, case reports, data notes and more

- The peer review process is transparent and collaborative

- Your article is indexed in PubMed after passing peer review

- Dedicated customer support at every stage

For pre-submission enquiries, contact research@f1000.com 